\title{
GRUPOS DE CONSENSO: UMA PROPOSTA DE APRENDIZAGEM COLABORATIVA PARA O PROCESSO DE ENSINO-APRENDIZAGEM
}

\section{Consensual Groups: a collaborative learning proposal for the teaching-learning process}

\author{
Patrícia Lupion Torres ${ }^{1}$ \\ Paulo R. Alcantara ${ }^{2}$ \\ Esrom Adriano Freitas Irala ${ }^{3}$
}

\section{Resumo}

Este artigo apresenta considerações teóricas e práticas sobre o conceito de Aprendizagem Colaborativa. Em uma proposta de Aprendizagem Colaborativa, os alunos constroem coletivamente seu conhecimento por meio de uma troca constante de informações, de pontos de vista, de questionamentos, de resoluções de questões e de avaliações. Este modelo de aprendizagem tem demonstrado ser efetiva em aumentar o nível acadêmico dos estudantes e em desenvolver habilidades de trabalho em grupo. Estudos reportam que estudantes que aprendem em grupos pequenos demonstram maior realização do que estudantes que foram expostos à instrução sem trabalho cooperativo ou colaborativo. Primeiramente, buscou-se uma conceituação do termo colaboração e a sua diferenciação com o termo cooperação, assim como uma perspectiva histórica do desenvolvimento da Aprendizagem Colaborativa. A partir desse resgate conceitual e histórico, apresenta-se uma proposta para a implementação da Aprendizagem Colaborativa na prática pedagógica por meio da aula de grupos de consenso, sugerindo-se um planejamento

1 Doutora em Engenharia de Produção - Mídia e Conhecimento, Mestre em Educação pela PUCPR, Pedagoga, Diretora da Área de Educação da Pontifícia Universidade Católica do Paraná (PUCPR). Rua Imaculada Conceição, 1155, Prado Velho, Curitiba - PR, CEP 80.215-901.

2 Ph.D. em Educação e Desenvolvimento Humano e Mestre em Educação pelo George Peabody College of Vanderbilt University, professor do Programa de Mestrado em Educação da PUCPR, coordenador da Linha de Pesquisa Educação, Comunicação e Tecnologia e professor da Graduação em Pedagogia da PUCPR. Rua Imaculada Conceição, 1155, Prado Velho, Curitiba - PR, CEP 80.215-901.

3 Mestrando em Educação na PUCPR. Graduado em Letras Inglês pela UFPR, professor do Centro de Línguas Positivo. 
adequado de todas as etapas do processo ensino-aprendizagem para o sucesso das atividades de Aprendizagem Colaborativa. Assim, foram considerados quatro conceitos da psicologia social para o planejamento de uma proposta de Aprendizagem Colaborativa: logística, estratégia, tática e técnica. Espera-se que o planejamento cuidadoso de todas as atividades de tal proposta possa provocar rupturas, desafiando os educandos e levando-os a formar uma comunidade de aprendizagem coesiva e reflexiva, cujos membros trabalhem para alcançar objetivos comuns enquanto respeitam a diversidade de idéias, valores, crenças e estilos de vida uns dos outros.

Palavras-chave: Aprendizagem colaborativa; Aprendizagem cooperativa; Grupos de consenso; Psicologia social.

\section{Abstract}

This article presents theoretical and practical considerations about the Collaborative Learning concept. In a Collaborative Learning proposal, students construct their knowledge collectively through a constant exchange of information, viewpoints, questionings, question resolutions and evaluations. This learning model has demonstrated its effectiveness in augmenting the students' academic level and in developing group work skills. Studies report that students who learn in small groups demonstrate a greater achievement than those who were instructed without cooperative or collaborative work. Firstly, this article sought a conceptualization of the term collaboration and its distinction with the term cooperation, as well as a historical perspective in the development of Collaborative Learning. From this conceptual and historical framework, a proposal is presented for the implementation of Collaborative Learning in the pedagogical practice through classes of consensual groups, suggesting a suitable planning for all the steps of the teachinglearning process for the success of the Collaborative Learning activities. Thus, four concepts from social psychology were considered for planning such proposal: logistic, strategy, tactics and technique. The careful planning of all activities of such a proposal is expected to provoke ruptures, challenging students and leading them to form a learning community, cohesive and reflective, whose members work to reach commom goals while respecting de diversity of ideas, values, beliefs and lifestyles of each other.

Keywords: Collaborative learning; Cooperative learning; Consensual groups; Social psychology.

\section{Introdução à aprendizagem colaborativa}

Muitas pessoas acreditam que o conhecimento é uma entidade que se transfere de uma cabeça para outra. A aprendizagem colaborativa, no entanto, parte da idéia de que o conhecimento é resultante de um consenso 
entre membros de uma comunidade de conhecimento, algo que as pessoas constroem conversando, trabalhando juntas direta ou indiretamente (i.e., resolução de problemas, projetos, estudos de caso, etc.) e chegando a um acordo.

Aprendizagem Colaborativa é uma estratégia de ensino que encoraja a participação do estudante no processo de aprendizagem e que faz da aprendizagem um processo ativo e efetivo. É um conjunto de abordagens educacionais também chamadas de aprendizagem cooperativa ou aprendizagem em grupo pequeno.

\section{Cooperação ou colaboração?}

Existe uma discussão quanto ao significado das palavras cooperação e colaboração. Há pesquisadores que acreditam que o termo cooperação é mais abrangente com distinções hierárquicas de ajuda mútua, ao passo que na colaboração existe um objetivo comum entre as pessoas que trabalham em conjunto sem uma hierarquia (NITZKE, CARNEIRO; GELLER, 1999). A revisão bibliográfica sobre o tema permite constatar que freqüentemente utilizam-se os termos cooperação e colaboração como sinônimos. Porém, cada um deles, ao longo dos anos, desenvolveu distinções próprias e diferentes práticas em sala de aula.

Muitos autores na literatura atual definem a aprendizagem cooperativa como uma aprendizagem mais estruturada, com técnicas de sala de aula mais prescritivas e com regras mais definidas de como deve se processar a interação entre os alunos, se comparada com a aprendizagem colaborativa, (MATTHEWS et al., 1995; OLSEN; KAGAN, 1992 apud OXFORD, 1997, p. 444). Olsen; Kagan, citados por Oxford (1997, p. 443), definem a aprendizagem cooperativa como:

uma atividade de aprendizagem em grupo organizada de tal maneira que a aprendizagem seja dependente da troca de informações socialmente estruturada entre os alunos em grupos e na qual cada aluno é responsável por sua própria aprendizagem e é motivado a contribuir com a aprendizagem dos outros.

Kagan $(1989,1990)$ formulou uma definição muito pertinente da aprendizagem cooperativa em um artigo da Revista Educational Leadership (Dez./ Jan./1989/1990). Ele destacou as estruturas gerais que caracterizam esse tipo de interação, aplicáveis a qualquer situação. Para ele, a implementação da aprendizagem cooperativa é baseada na criação, análise e aplicação sistemática de estruturas, ou formas de organização da interação social em sala de aula. Propõe que tais estruturas sigam uma série de etapas com normas bem defini- 
das para cada uma delas. Essas estruturas garantem um conjunto de procedimentos que promovem a interatividade entre grupos de alunos, permitindo, assim, que eles alcancem mais facilmente seu objetivo comum relativo ao conteúdo proposto (KAGAN, 1989, 1990 apud PANITZ, 2003).

Para Dillembourg e Larocque apud Nitzke et al. (1999), a diferença entre a cooperação e a colaboração pode ser traduzida pelo modo como é organizada a tarefa pelo grupo. Para eles, na colaboração, todos trabalham em conjunto, sem distinções hierárquicas, em um esforço coordenado, a fim de alcançarem o objetivo ao qual se propuseram. Já na cooperação, a estrutura hierárquica prevalece e cada um dos membros da equipe é responsável por uma parte da tarefa.

De acordo com Panitz (1996): "A colaboração é uma filosofia de interação e um estilo de vida pessoal, enquanto que a cooperação é uma estrutura de interação projetada para facilitar a realização de um objetivo ou produto final." Assim, a Aprendizagem Colaborativa é uma filosofia de ensino, não apenas uma técnica de sala de aula.

Nas palavras de Panitz (1996):

Em todas as situações onde pessoas formam grupos, a Aprendizagem Colaborativa sugere uma maneira de lidar com as pessoas que respeita e destaca as habilidades e contribuições individuais de cada membro do grupo. Existe um compartilhamento de autoridade e a aceitação de responsabilidades entre os membros do grupo, nas ações do grupo. A premissa subjacente da aprendizagem colaborativa está baseada na construção de consenso por meio da cooperação entre os membros do grupo, contrapondo-se à idéia de competição, na qual alguns indivíduos são melhores que outros. Os praticantes da Aprendizagem Colaborativa aplicam essa filosofia na sala de aula, nas reuniões de comitê, com grupos comunitários, dentro de suas famílias e geralmente como um modo de viver e lidar com outras pessoas (p. 1).

Em contrapartida, a cooperação apresenta-se como um conjunto de técnicas e processos que grupos de indivíduos aplicam para a concretização de um objetivo final ou a realização de uma tarefa específica. É um processo mais direcionado do que o processo de colaboração e mais controlado pelo professor. Portanto, pode-se afirmar, de maneira geral, que o processo de cooperação é mais centrado no professor e controlado por ele, enquanto que na colaboração o aluno possui um papel mais ativo.

Paas (1999), citando Dillenbourg et al., ressalta uma outra diferença, relacionada ao aspecto da coordenação: "A coordenação nas atividades cooperativas é apenas obrigatória na montagem dos resultados parciais, enquanto a colaboração é uma atividade coordenada, sincronizada que é resultado de um esforço continuado de construir e manter uma concepção compartilhada de um problema". 
Segundo alguns autores, Cord (2000); Harassim (1995) (2000); Dillembourg e Larocque apud Nitzke et al. (1999); Paas, (1999), há uma diferença conceitual entre os termos cooperação e colaboração. O processo de colaboração pode ser mais complexo. Cord (2000), por exemplo, reconhece que:

no domínio do ensino/aprendizagem o trabalho colaborativo entre discentes e ou docentes se concretiza muito freqüentemente por um trabalho de equipe... Por trabalho colaborativo, nós designamos, por conseguinte, de uma parte, a cooperação entre os membros de uma equipe e, de outra, a realização de um produto final: a Internet apresenta-se neste tempo como a ferramenta adequada para colocar em operação as pedagogias colaborativas.

Essa autora interpreta o trabalho de equipe como a concretização do trabalho colaborativo. Estabelece uma subordinação da colaboração à cooperação ao observar que o trabalho colaborativo depende da cooperação entre os membros de uma equipe. Elege a Internet como a ferramenta adequada para esta proposta e determina a necessidade de um produto final.

Cunha Filho et al. (2000, p.63) também afirmam que no modelo cooperativo: "além da relação entre sujeitos é acrescida a possibilidade de cooperação entre eles e as entidades de software (os agentes), transformados em elementos facilitadores do processo de comunicação e aprendizagem em comunidades virtuais de grande porte". Para Daele (1998, p. 1), a aprendizagem colaborativa é: "um modelo de aplicação pedagógica de Internet que visa favorecer a colaboração entre pares por meio de troca de mensagens eletrônicas entre os estudantes de um grupo ou de uma classe."

$\mathrm{Na}$ concepção de Cord (2000), ainda, a aprendizagem colaborativa seria um modelo de aplicação pedagógica de Internet que visa a favorecer a colaboração entre pares e permite a troca de mensagens eletrônicas entre os estudantes de um grupo ou de uma turma. Desta forma, a Internet constitui-se em uma ferramenta para aprendizagem colaborativa. Todavia, a virtualidade instrumental da Internet se empobrece quando a autora esclarece o seu entendimento, restringindo-o à troca de mensagens eletrônicas como possibilidade de comunicação entre os membros do grupo ou da turma.

Todos esses autores atribuem à tecnologia a sustentação do processo cooperativo e ou colaborativo. Ou seja, a tecnologia oferece meios que facilitam o processo de cooperação e colaboração, seja ele educativo, seja ele do campo laboral.

De acordo com Harassim (1995), a aprendizagem colaborativa é vista como "qualquer atividade na qual duas ou mais pessoas trabalham juntas para criar significado, explorar um tópico ou melhorar habilidades" (apud PAAS, 1999). 
Ou seja, pode-se generalizar a idéia de que qualquer atividade desenvolvida em conjunto animada por um objetivo final que leve a aquisições determinadas é uma situação de aprendizagem colaborativa.

O quadro apresentado a seguir apresenta uma comparação conceitual entre a Aprendizagem Cooperativa e a Aprendizagem Colaborativa:

\section{QUADRO 1 - COMPARAC̄̃O CONCEITUAL ENTRE A APRENDIZAGEM COOPERATIVA E A APRENDIZAGEM COLABORATIVA}

\begin{tabular}{|c|c|c|}
\hline ASPECTOS & $\begin{array}{l}\text { APRENDIZAGEM } \\
\text { COOPERATIVA }\end{array}$ & $\begin{array}{l}\text { APRENDIZAGEM } \\
\text { COLABORATIVA }\end{array}$ \\
\hline Propósito & $\begin{array}{l}\text { Aumenta as habilidades cognitivas e } \\
\text { sociais por meio de um conjunto de } \\
\text { técnicas aprendidas. }\end{array}$ & $\begin{array}{l}\text { Promove a "aculturação" dos alunos } \\
\text { nas comunidades de conhecimento. }\end{array}$ \\
\hline Grau de estruturação & Alto & Variável \\
\hline Relacionamentos & $\begin{array}{l}\text { Os indivíduos são responsáveis pelo } \\
\text { grupo e vice-versa; o profess or } \\
\text { facilita, mas o grupo é primordial. }\end{array}$ & $\begin{array}{l}\text { Os alunos se engajam em atividades } \\
\text { com "companheiros mais capazes" } \\
\text { (professores, alunos mais avançados, } \\
\text { etc.) os quais dão assistência e os } \\
\text { guiam. }\end{array}$ \\
\hline Prescrição das atividades & Alta & Baixa \\
\hline Palavras-chave & $\begin{array}{l}\text { Interdependência positiva, } \\
\text { responsabilização, trabalho em } \\
\text { grupos, papéis definidos, estruturas. }\end{array}$ & $\begin{array}{l}\text { Zona de Desenvolvimento Proximal, } \\
\text { aprendizagem cognitiva, aculturação, } \\
\text { suporte mútuo, cognição situada, } \\
\text { indagação reflexiva, epistemologia. }\end{array}$ \\
\hline
\end{tabular}

Fonte: Oxford (1997, p. 444)

Partindo das idéias apresentadas no quadro comparativo, a aprendizagem cooperativa configura-se como um procedimento que possui uma série de técnicas altamente estruturadas psicológica e socialmente, que servem como auxílio aos estudantes no seu trabalho em grupo para a conquista de objetivos educacionais definidos. Por outro lado, a aprendizagem colaborativa é baseada em conceitos mais profundos, que englobam "questões teóricas, políticas e filosóficas tais como a natureza do conhecimento como uma construção social e o papel da autoridade na sala de aula" (MATTHEWS et al., p. 4).

Resumindo, portanto, observa-se, nesses diversos conceitos, que os termos "cooperação" e "colaboração" designam atividades de grupo que pretendem um objetivo em comum. Apesar de suas diferenciações teóricas e práticas, ambos os conceitos derivam de dois postulados principais: de um lado, da rejeição ao autoritarismo, à condução pedagógica com motivação hierárquica, unilateral. De outro, trata-se de concretizar uma socialização não só pela aprendizagem, mas principalmente na aprendizagem. Desta forma, 
estes dois propósitos se organizariam mediante um instrumento que equaciona a comunicação com tais características: trata-se de uma comunicação direta, contínua, construtiva.

Considerando o anteriormente exposto, optou-se por explorar, neste trabalho, o sentido da aprendizagem colaborativa. Entende-se por aprendizagem colaborativa o processo de reaculturação que ajuda os estudantes a se tornarem membros de comunidades de conhecimento cuja propriedade comum é diferente daquelas comunidades que já pertencem. Refere-se a uma passagem para outra cultura, para outro ambiente que possua outras normas, valores diferenciados daquele que nos encontramos. O acesso a uma comunidade depende da aquisição de características especiais dos membros desta comunidade. A mais importante delas é a fluência na linguagem que constitui a comunidade, a linguagem com a qual os membros da comunidade constroem o conhecimento que é a sua propriedade comum. Assume, portanto, que o conhecimento é socialmente construído e que a aprendizagem é um processo sociolingüístico (BRUFFEE, 1993, 1999).

\section{Perspectivas históricas no desenvolvimento da aprendizagem colaborativa}

O conceito de aprendizagem colaborativa, isto é, de aprender e trabalhar em grupo, embora pareça novo, tem sido testado e implementado por teóricos, pesquisadores e educadores desde o século XVIII. O método de aprendizagem por colaboração tem sido usado por professores das mais variadas disciplinas, com o objetivo de preparar seus alunos de forma mais efetiva para os desafios encontrados fora do âmbito escolar. Corporações de trabalho também têm adotado o método de aprendizagem e trabalho em grupo, visto que a habilidade de produzir em grupos, em colaboração com outros, é uma habilidade muito valorizada em empresas e repartições.

A metodologia de aprendizagem colaborativa no ensino de habilidades de escrita foi utilizada pelo professor de lógica e filosofia da Universidade de Glasgow, George Jardine, entre os anos de 1774 e 1826. Por meio do ensino de técnicas de comunicação e de trabalho em grupo e de técnicas de composição de textos em colaboração, esse professor tinha a pretensão de tornar seus alunos aptos à plena participação na sociedade britânica (GAILLET, 1994). Segundo pesquisas de Johnson e Johnson (1992,1998), as experiências da Lancaster School e a Common School Movement, no começo do século XIX, foram uma das primeiras experiências de aprendizagem cooperativa em grupos em um ambiente de educação formal. No final do século XIX, a aprendizagem em grupo foi promovida em escolas públicas dos Estados 
Unidos pelo Coronel Francis Parker, um superintendente de escolas públicas. A escola distrital de Parker foi exemplar na implementação da aprendizagem cooperativa no âmbito educacional, atraindo a atenção de milhares de educadores, que foram até ela interessados em assistir à aprendizagem cooperativa em ação (JOHNSON; JOHNSON 1992, 1998, apud GILLIAM, 2002).

O movimento da Escola Nova, no começo do século XX, embasado por teorias de educadores como John Dewey, Maria Montessori e Jean Piaget, foi uma grande influência para a Aprendizagem Colaborativa. De acordo com Behrens (1999, p. 47 - 48):

A Escola Nova foi acolhida no Brasil, proposta por Anísio Teixeira, por volta de 1930, num momento histórico de efervescência de idéias, aspirações e antagonismos políticos, econômicos e sociais. Apresenta-se como um movimento de reação à pedagogia tradicional e busca alicerçar-se com fundamentos da biologia e da psicologia dando ênfase ao indivíduo e sua atividade criadora.

Assim, a Escola Nova buscou um resgate da figura do aluno e suas necessidades, dando a ênfase à sua participação mais efetiva na ação educativa. Nesse contexto, a metodologia de trabalho em grupo tornou-se importante para o ideário escolanovista. Dewey promoveu grupos de aprendizagem cooperativa como parte de seu método de instrução.

John Dewey chamou de "vida associada" as atividades nas quais os relacionamentos humanos são a chave para o bem-estar e o sucesso. Bruffee (1995, p. 12) conta que a idéia de "vida associada" na educação americana remonta aos tempos de Benjamin Franklin. Ele nos diz que Franklin organizou grupos de aprendizado para que ele pudesse perseguir sua própria educação, nos tempos em que, quando jovem, morava na cidade de Boston do tempo colonial em condições de quase pobreza. Em estudos sobre as pedagogias colaborativas da década de 1920 até a década de 1950, citadas por Bruffe nesse mesmo artigo, são exploradas as freqüentes tentativas dos americanos de institucionalizarem educacionalmente a "vida associativa". (p.14)

Ainda nessa época, foi desenvolvida a Teoria da Interdependência Social e Dinâmica de grupo pelos psicólogos da Gestalt, Kurt Koffka e Kurt Lewin. (JOHNSON; JOHNSON, apud GILLIAM, 2002). Também no início do século XX, surgiu a Pedagogia Freinet. O pedagogo francês Célestin Freinet realizou uma nova e revolucionária forma de ensino no início desse século, centrando sua pedagogia na preocupação de desenvolver ao máximo as potencialidades do aprendiz. Por meio de técnicas como o texto livre, o jornal escolar, os planos de trabalho, a cooperativa escolar e a biblioteca de trabalho, esse pedagogo procurou "diversificar as atividades dos aprendizes, proporcionando atividades que lhes permitiam conhecer-se, afirmar-se e, assim valorizar suas qualidades pessoais". (ARRIADA et al., 2000, p. 10). 
Na década de 1950 surgiram as Teorias da Aprendizagem Cognitiva formuladas por Jean Piaget e Lev Vygotsky (PALANGANA, 1994). Os estudos de Jean Piaget buscavam conhecer a dinâmica do processo de construção do conhecimento pelo indivíduo. Sua teoria era predominantemente de base interacionista, pois o sujeito era visto como um ser ativo que se relacionava com o meio físico e social, construindo relações significativas com estes. Para Piaget, a interação entre indivíduos e o intercâmbio de idéias promovia o desenvolvimento cognitivo do sujeito, pois os conhecimentos são socialmente definidos e o sujeito depende da interação social para construção e validação dos conceitos. (VALADARES, apud VALASKI, 2003, p. 23). VYGOTSKY foi o principal expoente da Teoria Sociocultural que enfatizava o papel da interação social no desenvolvimento do homem. Na interpretação de Rego apud Valaski (2003, p. 24): "ele Vygotsky considera que o indivíduo é um ser social e que constrói sua individualidade a partir das interações que se estabelecem entre os indivíduos, mediadas pela cultura". Assim, as teorias desses dois pensadores influenciaram enormemente o desenvolvimento de metodologias de Aprendizagem Colaborativa, pois pregavam a interação como base da aprendizagem e desenvolvimento cognitivo.

Na década de 1960, muitas pesquisas foram realizadas sobre os temas de cooperação e competição em crianças por Kagan, Movimento de Aprendizagem por Investigação, Bruner; Suchman com Aprendizagem Programada e Modificação de Comportamento (SKINNER). No final dessa mesma década, David e Roger Johnson começaram a treinar alguns professores em aprendizagem cooperativa na Universidade de Minnesota (JOHNSON; JOHNSON, apud GILLIAM, 2002). Na Inglaterra, também nos anos 60, um grupo de professores britânicos do ensino médio começou a desenvolver práticas com idéias colaborativas. Durante a guerra do Vietnã, os professores colegas Edwin Mason, Charity James, e Leslie Smith, da Faculdade Goldsmith, da Universidade de Londres, comprometeram-se em democratizar a educação, eliminando formas autoritárias de educação na sua prática pedagógica. O trabalho colaborativo proposto por Mason e seus colegas já tinha sido anteriormente realizado pela bióloga M. Abercrombie (1964) no contexto da educação médica. Após 10 anos de pesquisa, ela chegou à conclusão de que a arte do julgamento médico é melhor aprendida em pequenos grupos, nos quais os estudantes alcançam os diagnósticos colaborativamente (BRUFEE, 1984).

No começo da década de 1970, muitos professores de universidades americanas começaram a notar a crescente dificuldade que os alunos que ingressavam nas instituições de ensino superior apresentavam para serem bemsucedidos nos seus estudos acadêmicos e para adaptarem-se às convenções da sala de aula universitária. Tomando como base teorias sobre a organização social da aprendizagem de autores como Bremer, Moschzisker e outros auto- 
res dessa época, esses professores chegaram à conclusão de que precisavam de uma alternativa ao método tradicional de ensino-aprendizagem de sala de aula, a fim de que eles pudessem oferecer uma melhor preparação aos estudantes (BRUFEE, 1984). Assim, algumas faculdades americanas começaram a adotar técnicas de instrução e avaliação em pares e em grupos, trabalho esse classificado como Aprendizagem Colaborativa. De acordo com Brufee (1984), o que distinguia a aprendizagem colaborativa dos métodos tradicionais de sala de aula era que aquela parecia não tanto mudar o que as pessoas aprendiam, mas o contexto social no qual os alunos aprendiam. Nesse novo contexto, a força educativa poderosa do trabalho em grupo, tanto desperdiçada pelos métodos tradicionais de ensino, foi revitalizada pela nova postura de trabalho dos educadores.

Portanto, na década de 1970, houve muita produção na área da aprendizagem cooperativa e colaborativa. David Johnson escreveu Psicologia Social da Educação e Robert Hamblin desenvolveu pesquisas comportamentais sobre cooperação e competição. Ainda nos anos 70, ocorreu a primeira conferência internacional sobre aprendizagem colaborativa em Tel Aviv, Israel e também o Jornal de Pesquisa e Desenvolvimento em Educação lançou uma edição sobre cooperação (JOHNSON; JOHNSON, apud GILLIAM, 2002).

Todavia, somente na década de 1990 a Aprendizagem Colaborativa ganha popularidade entre educadores do ensino superior. David e Roger Johnson e Karl Smith adaptam a aprendizagem cooperativa para a sala de aula de faculdades e escrevem Aprendizagem Ativa: Cooperação na Sala de Aula Universitária.

Gilliam (2002, p. 45), a fim de apresentar de forma mais didática a cronologia da aprendizagem cooperativa/colaborativa, elabora o seguinte quadro baseado em pesquisas de Johnson e Johnson (1992, 1998). 
Grupos de consenso: uma proposta de aprendizagem colaborativa para o processo de ...

\section{QUADRO 2- LINHA DO TEMPO: HISTÓRIA DA APRENDIZAGEM COOPERATIVA}

\begin{tabular}{|c|c|}
\hline Data & Evento Relacionado \\
\hline $\begin{array}{l}\text { Começo } \\
\text { do século } \\
\text { XX }\end{array}$ & $\begin{array}{l}\text { A Escola Lancaster se estabeleceu nos Estados Unidos (Joseph Lancaster e Andrew Bell } \\
\text { usaram grupos de aprendizagem cooperativa extensivamente na Europa e trouxeram a idéia } \\
\text { para os EUA em 1806, Nova York). } \\
\text { O Movimento da Escola Comum nos EUA: forte ênfase na aprendizagem cooperativa. }\end{array}$ \\
\hline $\begin{array}{l}\text { Final do } \\
\text { século XIX }\end{array}$ & $\begin{array}{l}\text { Coronel Frances Parker: Promoveu a aprendizagem cooperativa, democracia e a devoção à } \\
\text { liberdade nas escolas públicas. }\end{array}$ \\
\hline $\begin{array}{l}\text { Começo do } \\
\text { século XX }\end{array}$ & $\begin{array}{l}\text { Movimento da Escola Nova: John Dewey e outros; Dewey promoveu grupos de } \\
\text { aprendizagem cooperativa como uma parte do seu famoso projeto de método de instrução. } \\
\text { Teoria da Interdependência Social \& Dinâmica de Grupo: Kurt Koffka \& Kurt Lewin, } \\
\text { Psicólogos da Gestalt. }\end{array}$ \\
\hline Anos 40 & Teorias e pesquisas sobre cooperação e competição: Morton Deutsch. \\
\hline Anos 50 & $\begin{array}{l}\text { Teoria da aprendizagem cognitiva: Jean Piaget e Lev Vygotsky. } \\
\text { Movimento de dinâmica em grupo aplicado, Deutsch, Laboratórios Nacionais de } \\
\text { Treinamento. } \\
\text { Pesquisas de Deutsch sobre confiança, situações individualistas; Estudos Naturalísticos. }\end{array}$ \\
\hline Anos 60 & $\begin{array}{l}\text { Pesquisas de Stuart Cook sobre cooperação. } \\
\text { Pesquisas de Spencer Kagan sobre cooperação e competição em crianças. } \\
\text { Movimento de Aprendizagem por Investigação (descoberta): Bruner, Suchman. } \\
\text { B. F. Skinner, Aprendizagem Programada, Modificação de Comportamento. } \\
\text { David e R oger Johnson começaram a treinar professores em aprendizagem cooperativa na } \\
\text { Universidade de Minnesota. }\end{array}$ \\
\hline Anos 70 & $\begin{array}{l}\text { David Johnson escreveu Psicologia Social da Educação. } \\
\text { Robert Hamblin: Pesquisa comportamental sobre cooperação / competição. } \\
\text { Primeiro Simpósio Anual de AP A (Entre os apresentadores estavam David e Roger Johnson, } \\
\text { Stuart Cook, Elliot Aronson, Elizabeth Cohen, e outros). } \\
\text { Revisão das pesquisas de David e Roger Johnson sobre cooperação / competição. } \\
\text { Robert Slavin começou o desenvolvimento de currículos cooperativos. } \\
\text { Shlomo e Yael Sharan, Ensino em pequenos grupos (Investigação em grupo). } \\
\text { Elliot Aronson, Sala de aula Jigsaw (quebra-cabeça). } \\
\text { Edição sobre Cooperação do Jornal de Pesquisa e Desenvolvimento em Educação. } \\
\text { Primeira conferência Intemacional sobre aprendizagem cooperativa, Tel Aviv, Israel. }\end{array}$ \\
\hline Anos 80 & $\begin{array}{l}\text { David e Roger Johnson, Meta-análise de Pesquisa em Cooperação. } \\
\text { Elizabeth Cohen, Desenhando Grupos de Trabalho. } \\
\text { Spencer Kagan desenvolveu Abordagens Estruturais para Aprendizagem Cooperativa. } \\
\text { David e Roger Johnson escreveram Cooperacão \& Competicão: Teoria \& Pesquisa. }\end{array}$ \\
\hline Anos 90 & $\begin{array}{l}\text { A aprendizagem cooperativa ganha popularidade entre educadores do ensino superior. } \\
\text { Primeira conferência anual sobre Liderança em Aprendizagem Cooperativa, Minneapolis. } \\
\text { David e Roger Johnson e Karl Smith adaptaram a aprendizagem cooperativa para a sala de } \\
\text { aula de faculdades, e escreveram. Aprendizagem Ativa: Cooperação na Sala de Aula da } \\
\text { Faculdade. }\end{array}$ \\
\hline
\end{tabular}

FONTE: Adaptada de JOHNSON, D. W., \& JOHNSON, R. T. (1992). Implementing cooperative learning. Contemporary Education. 63 (3), 173 - 181. e de JOHNSON, D. W., JOHNSON, R. T., \& SMITH, K. A. (1998a). Active learning: Cooperation in the college classroom (pp. A:2 - A: 4). Edina, MN. Interaction Book Company. 


\section{Fazendo aprendizagem colaborativa}

Aprendizagem Colaborativa tem demonstrado ser efetiva em aumentar o nível acadêmico dos estudantes e em desenvolver habilidades de trabalho em grupo.

Um relatório da AMERICAN ASSOCIATION FOR THE ADVANCEMENT OF SCIENCE (1989) advertiu que "a natureza colaborativa do trabalho científico e tecnológico deveria ser fortemente reforçado por atividades freqüentes de grupo na sala de aula. Cientistas e engenheiros trabalham na maior parte do tempo em grupos e menos freqüentemente como investigadores isolados. Igualmente, estudantes deveriam ganhar experiência compartilhando responsabilidade para aprender uns com os outros" (p. 148).

Springer, Stanne e Donovan (1997) reportaram que estudantes que aprenderam em grupos pequenos demonstraram maior realização do que estudantes que foram expostos à instrução sem trabalho cooperativo ou colaborativo. Os mesmos efeitos foram encontrados ao analisarem atitudes e persistência em cursos e programas. Em uma proposta de aprendizagem em molde colaborativo, os alunos constroem coletivamente seu conhecimento por meio de uma troca constante de informações, de pontos de vista, de questionamentos, de resoluções de questões, de avaliações.

A colaboração entre os pares permite uma produção coerente e única do grande grupo, tanto nas atividades dos subgrupos quanto nas atividades individuais, visto que todas são compartilhadas por todos os membros que compõem a turma, por meio da publicação das atividades. O grupo é, pois, antes de qualquer coisa, uma ferramenta, um instrumento a serviço da construção coletiva do saber.

São as atividades que dão sentido à ação do grupo ao mesmo tempo em que o dinamizam. É no processo de gestão destas atividades que os componentes do grupo se organizam, repartem papéis, discutem idéias e posições, interagem entre si, definem subtarefas, tudo isso, dentro de uma proposta elaborada, definida e negociada coletivamente.

As estratégias pedagógicas são centradas na construção do conhecimento e na colaboração entre pares. Colaboração esta que não visa a uma uniformização, já que respeita os alunos como indivíduos diferentes, que na heterogeneidade produzem e crescem juntos.

Mahieu (2001, p.23), ao referir-se à equipe, para ele entendida como grupo de pessoas colaborando para um mesmo trabalho, afirma que "... a equipe deve confrontar as realidades, gestionar a pluralidade, do previsto ao imprevisto, da descoberta e da busca da complementaridade numa pesquisa permanente de coerência e não de uniformidade".

É na heterogeneidade que se estabelecem novas formas de relações 
entre pares. Ao desenvolver atividades em grupo, é preciso gerenciar conflitos sociocognitivos, propor alternativas, rever conceitos, discutir posições, repartir cargas cognitivas, reelaborar idéias, repartir autorias, negociar e muitas vezes exercer um processo de auto e mútua-regulação.

No ensino tradicional, a avaliação é baseada no trabalho submetido por indivíduos. Para encorajar o trabalho colaborativo entre estudantes, alguma forma de avaliação de grupo é necessária além da avaliação individual. A avaliação de grupo deve sempre incentivar a colaboração, desfavorecendo a competição.

\section{Uma proposta de aprendizagem colaborativa}

Uma proposta de aprendizagem colaborativa é a aula de grupos de consenso. Nela as pessoas trabalham colaborativamente numa tarefa ou atividade, negociando entre elas o que acreditam e sabem para alcançar algum tipo de consenso ou acordo. Na organização destes grupos, os professores geralmente: (a) dividem a turma em grupos pequenos (de dois a seis participantes, dependendo da tarefa); (b) providenciam uma tarefa, previamente definida, para os grupos pequenos; (c) re-agrupam a turma numa sessão plenária para ouvir os relatos dos grupos pequenos e negociar com o grupo todo; e (d) avaliam a qualidade do trabalho dos estudantes.

O professor na aprendizagem colaborativa deve criar atividades que ajudem os estudantes a descobrirem e tirarem vantagem da heterogeneidade do grupo para aumentar o potencial de aprendizagem de cada membro do grupo.

\section{Planejamento para a sala de aula}

O sucesso das atividades de aprendizagem colaborativa depende do planejamento cuidadoso de todas as etapas do processo ensino-aprendizagem. Na sala de aula tradicional, a autoridade, o controle e a estrutura do curso estão bem definidos. As técnicas de aprendizagem colaborativa não só mudam o ensino e aprendizagem como também a estrutura de autoridade e controle na classe. As atividades de grupo sugerem uma estrutura diferente. Qualquer estratégia instrucional baseada nestas abordagens prevê a organização, a estruturação e a sistematização dos elementos que compõem as experiências curriculares, a fim de garantir que os alunos sejam conduzidos pelos caminhos adequados que o levem a atingir o objetivo final proposto. As estratégias educacionais estão centradas na tecnologia educacional para transmissão e recepção de informações. 
Quando se trata de planejar uma proposta de aprendizagem colaborativa, julga-se imprescindível considerar quatro conceitos (retirados do vocabulário militar) já amplamente divulgados por Pichon Riviera apud Visca (p.18); na psicologia social: logística, estratégia, tática e técnica. Entende-se por logística neste trabalho a possibilidade de levar em conta as características do aluno ou do grupo em relação às características do professor, cuja derivação em ambas é dada pela formação pessoal e profissional e pelos traços de personalidade. A estratégia é a arte de dirigir as operações, utilizando-se de categorias conceituais como: tempo, lugar, freqüência, duração, materiais, custos, interrupções regradas, etc. A tática é a implementação, é o colocar em prática o plano elaborado, e a técnica é a forma como se opera.

Devem-se considerar também os seguintes fatores quando o professor decide incorporar ou iniciar seu trabalho utilizando esta proposta de aprendizagem colaborativa: (a) É a primeira vez ensinando este curso?; (b) O professor é experiente com as atividades de aprendizagem colaborativa?; (c) $\mathrm{O}$ professor enfrenta riscos ou não?; (d) Qual é o nível de conforto do professor ao tentar coisas novas?; e (e) Qual é o estilo de ensino do professor?

Em geral, se o professor é novo no curso ou em aprendizagem colaborativa, seria prudente modificar só uma parte do curso.

Se o professor não se sentir confortável com aprendizagem colaborativa ou tem aversão a riscos, seria prudente incorporar só uma atividade de aprendizagem colaborativa no curso.

Importante também considerar: (a) o número de estudantes no curso; (b) o perfil dos estudantes; (c) se os estudantes são graduados ou não; e (d) o nível de experiência de aprendizagem do grupo de estudantes.

Vale destacar que é muito importante que os objetivos do curso e sua estrutura harmonizem-se, para tal o professor deve perguntar-se: (a) Que conhecimento e habilidades o professor deseja que seus estudantes adquiram no curso? e (b) Em se tratando de atividades de grupo com novos grupos ou estudantes inexperientes, o professor deve rever a estrutura de grupo, o papel de cada membro do grupo e as habilidades sociais necessárias para a realização das atividades?

\section{Considerações finais}

É fundamental para o sucesso de uma proposta de aprendizagem colaborativa que todas as atividades sejam planejadas de modo a provocar rupturas, a desafiar os educandos, levando-os a formar uma comunidade de aprendizagem coesiva e reflexiva, cujos membros trabalhem para alcançar objetivos comuns enquanto respeitam a diversidade de idéias, valores, crenças e estilos de vida. 
Com as atividades planejadas, pretende-se um movimento espiral, uma sucessão de equilíbrios e desequilíbrios, um estar aberto para o novo, um coordenar do diálogo entre os conhecimentos e experiências anteriores e o que de novo se apresenta. Busca-se por meio de uma sucessão de atividades organizadas e com regras preestabelecidas promover rupturas que gerem situações de desequilíbrio com força suficiente para provocar mudanças, que levem o aluno a se assumir enquanto sujeito pesquisador e autônomo.

\section{Referências}

AMERICAN ASSOCIATION FOR THE ADVANCEMENT OF SCIENCE. Science for All Americans: Project 2061. New York: Oxford University Press, 1989. p.148. ARRIADA, M. C.; RAMOS, E. F. Como promover condições favoráveis à aprendizagem cooperativa suportada por computador? Florianópolis: Departamento de Informática e Estatística, Universidade Federal de Santa Catarina, 2000.

BEHRENS, M. A. O paradigma emergente e a prática pedagógica. Curitiba: Champagnat, 1999.

BRUFFEE, K. A. Collaborative Learning and the "Conversation of Mankind". College English, v. 46, n. 7, p. 635-652, nov. 1984. Press, 1993

Collaborative learning. Baltimore: The John Hopkins University

Sharing our toys: Cooperative learning versus collaborative learning. Change, p.12-18, jan./feb. 1995.

Collaborative learning: higher education, interdependence, and the authority of knowledge. 2nd edition. Baltimore: Johns Hopkins, 1999.

CORD, B. Internet et pédagogie - état des lieux. Disponivel em: <http:// wwwadm.admp6.jussieu.fr/fp/uaginternetetp/definition_travail_colboratif.htm> Acesso em: 04 jul. 2000.

CUNHA FILHO, P. C. et al. EAD.br: Educação à distância no Brasil na era da internet: o Projeto Virtus e a construção de ambientes virtuais de estudo cooperativo. São Paulo,SP: Anhembi Morumbi, 2000.

DAELE, A. Carnet de bord et portofolio en apprentissage collaboratif à distance. Disponível em: <http://bigbox.det.fundp.ac.be/ ada/memoire/ mititre.html> Acesso em: 04 jul. 2000 
GAILLET, L. L. A historical perspective on collaborative learning. Disponível em: <http://www.cas.usf.edu/JAC/141/gaillet.html> Acesso em: 09 mar. 2004.

GILLIAM, J. H. The impact of cooperative learning and course learning environment factors on learning outcomes and overall excellence in the community college classroom. Raleigh, 2002. Tese de Doutorado - Programa de Pós-Graduação, North Carolina State University.

HARASIM, L. On-Line Education: A New Domain. In: MASON, Robin; KAYE, Anthony (eds). Mindweave: Communication, Computers and Distance instruction. Oxford: Pergamon, 1989.

MAHIEV, P. Travailler em équipe. Paris: Hachette Education, 2001.

MATTHEWS, R. S. et al. Building bridges between cooperative and collaborative learning. Cooperative Learning and College Teaching Newsletter, v. 6, n. 1, p. 2-5.

Disponível em: <:http://www.csudh.edu/SOE/cl_network/RTinCL.html> Acesso em: 10 abr. 2004.

NITZKE, J.; GELLER, M.; CARNEIRO, M. Aprendizagem cooperativa/ colaborativa. Disponível em:< http://www.nie.ufrgs.br/ alunosspg99/mara/ menu.htm> Acesso em: 19 dez. 2000.

NITZKE, J.; CARNEIRO, M.; GELLER, M. Aprendizagem cooperativa / colaborativa apoiada por computador (ACAC). Trabalho apresentado no SBIE 1999. Disponível em: http://www.niee.ufrgs.br/ alunospg99/mara/ Acesso em: 28.01.2001.

OXFORD, R. L. Cooperative Learning, Collaborative Learning, and Interaction: three communicative strands in the language classroom. The Modern Language Journal, v. 81, n. 4, p. 443 - 456, 1997.

\section{PAAS, L. C. A integração da abordagem colaborativa à tecnologia internet} para aprendizagem individual e organizacional no PPGEP. Florianópolis, 1999. Dissertação (Mestrado) - Programa de Pós- Graduação em Engenharia de Produção da UFSC. Disponível em: <http://www.esp.ufsc.br/disserto99/ leslie/index.html > Acesso em: 19 dez..2000.

Palangana, I. C. Desenvolvimento $\&$ aprendizagem em Piaget e Vygotsky: a relevância do social. São Paulo,SP: Plexus, 1994.

PANITZ, T. A definition of collaborative vs cooperative learning. Disponível em: <http://www.lgu.ac.uk/deliberations/collab.learning/panitz2.html> Acesso em: 14 dez. 2003. 
SPRINGER, L.; STANNE, M. E.; DONOVAN, S. Effects of cooperative learning on academic achievement among undergraduates in science, mathematics, engineering, and technology: a meta-analysis (Unpublished Report). Madison, WI: University of Wisconsin- Madison and National Center for Improving Science Education, The National Institute for Science Education, April 1997.

VALASKI, S. A aprendizagem colaborativa com uso de computadores: uma proposta para a prática pedagógica. Curitiba, 2003. 107 f. Dissertação (Mestrado em Educação) - Setor de Ciências Humanas e Teologia, Pontifícia Universidade Católica do Paraná.

VISCA, J. Clínica psicopedagógica: epistemologia convergente. Porto Alegre: Artes médicas, 1987. 